\title{
The Significance of Group Supervision to Yogo Teachers in Japan
}

\author{
Kazuko Iwasaki $^{1,2}$, Toshiyuki Watanabe ${ }^{3}$, Takeshi Tamura ${ }^{4}$ \\ ${ }^{1}$ Takasaki University of Health and Welfare, The Department of Health and Welfare Doctor's Course, Takasaki, Japan \\ ${ }^{2}$ Maebashi Municipal Amagawa Elementary School, School Health Room, Maebashi, Japan \\ ${ }^{3}$ Takasaki University of Health and Welfare, Department of Health and Welfare, Takasaki, Japan \\ ${ }^{4}$ Tamura Takeshi Research Institute. Tokyo, Japan \\ Correspondence: Kazuko Iwasaki, Takasaki University of Health and Welfare, The Department of Health and Welfare \\ Doctor's Course, Takasaki, Japan; Maebashi Municipal Amagawa Elementary School, School Health Room, Maebashi, \\ Japan.
}

Received: July 5, $2017 \quad$ Accepted: August 9, $2017 \quad$ Online Published: August 10, 2017

doi:10.11114/jets.v5i9.2587 URL: https://doi.org/10.11114/jets.v5i9.2587

\begin{abstract}
This study aimed to evaluate the significance of group supervision to Yogo teachers in Japan, who often deal with work-related problems in isolation. Like school nurses in the United States, the role of the Yogo teacher is to oversee students' health education and management. In this study, eight Yogo teachers, each with a minimum of six years' experience, attended six supervised group sessions in 2016. During each session, one participant presented a case, and all participants then engaged in a general exchange of opinions about the case. Following the six sessions, semi-structured interviews were conducted with the participants, and the interview data were analyzed using M-GTA (modified grounded theory approach). The results generated 14 concepts and six categories, schematizing the Yogo teachers' change of consciousness in relation to each category. The Yogo teachers evidenced needs in the categories of "Emotional Support," "Awareness," "Systemic Thinking," "Collaboration," "Motivation Improvement," and "Training Location." Ultimately, the study demonstrated that supervision by family therapists improved education by enhancing Yogo teachers' consultation abilities and systemic thinking. Yogo teachers' participation in the group supervision resulted in the following change in consciousness: their awareness was deepened by receiving emotional support, by training with the intent to learn, and by considering the significance of collaboration. Overall, teachers experienced an increase in self-motivation. The process for "Improvement of consultation ability" also became clear. Thus, group supervision by psychiatrists and/or family therapists has a positive impact on the overall motivation and work efficacy of Yogo teachers in Japan.
\end{abstract}

Keywords: Yogo teacher (school nurse), supervision, family therapist, psychiatrist, M-GTA

\section{Introduction}

In Japan, the role of the Yogo teacher is equivalent to that of a school nurse in the United States, but the Yogo teacher is positioned as a teacher rather than a nurse. The role of the Yogo teacher is to provide health management and health education for students. Nationwide, Japan employs approximately 40,000 Yogo teachers, 99.9\% of whom are women. Most male Yogo teachers engage in more specialized work, such as in support schools for children with developmental disabilities.

Every day, Yogo teachers work in the health department, building trust with children while treating small injuries and fevers, obtaining psychological information, and learning background family information (Kouno et al., 2013a). In Japan in particular, there are many psychological problems that lie behind the injuries and illnesses of children who come to the school health room (Miki, 2013; Iwasaki, 2015). Iwasaki and Watanabe (2016) noted that Yogo teachers have counseling knowledge and skills for the early detection of psychological problems, and provide important care not just for children's bodies, but also for their minds.

In a 2016 nationwide survey on "Training I'd like to receive," which was administered to 536 Yogo teachers, the respondents noted that the most frequent training need in elementary school was "understanding and response to the mind" (22.0\%; Iwasaki \& Watanabe, 2017). It thus became clear that modern Japanese Yogo teachers require specific counseling theories and skills, similar to those received by other experts such as psychiatrists, clinical psychologists, 
school social workers, and so on. It was also found that holding case study meetings and utilizing teacher supervision will be important means of delivering such training in the future (Iwasaki \& Watanabe, 2017). However, while case studies that deal exclusively with Yogo teachers have been reported, to date there has been no single paper on the effect of Yogo teachers' collaboration with psychiatrists, clinical psychologists, school social workers, and others. To deal with the psychological problems that affect children, we believe that collaboration with psychiatrists specializing in family therapy is appropriate. We also need to engage Yogo teachers more directly with the family members of the children they treat.

To highlight this need, this study demonstrates the training effects of Yogo teacher group supervision by showing how Yogo teachers perceived changes in their consciousness when they participated in group supervision (GSV) with psychiatrists and family therapists.

\section{Method}

\subsection{Survey Target}

Eight Yogo teachers participated in this research. Each had a minimum of six years' experience working in their schools. The Ministry of Education, Culture, Sports, Science and Technology provides training to Yogo teachers in the fifth year after graduation; thus, if an individual had more than six years' experience, he or she was recognized as a Yogo teacher at the educational site in which he or she was working. The participants were aged between 31 and 53 years old, with an average age of 43. The profiles of the participants are shown in Table 1.

Table 1. Profiles of participants

\begin{tabular}{clccc}
\hline Participants & Sex & Age & Yrs. Experience & School Type \\
\hline A & Female & 52 & 32 & Elementary \\
\hline B & Female & 50 & 21 & Junior High \\
C & Female & 53 & 31 & Elementary \\
D & Female & 41 & 17 & Elementary \\
E & Female & 35 & 9 & Junior High \\
F & Female & 31 & 9 & Junior High \\
G & Female & 39 & 15 & Junior High \\
H & Female & 44 & 13 & Junior High \\
\hline
\end{tabular}

\subsection{Study Period}

From May to November 2016, supervision was held once a month, six times in total, for two hours per session. The participants met in the office of the supervisor. At each meeting, one participant presented a case related to the problems encountered by Yogo teachers (for instance, in correspondence with parents, children, school officials, etc.). All participants then exchanged comments and opinions about the case, giving and receiving important feedback.

\subsection{Interview Survey on Supervision Experience}

\subsubsection{Interview Period}

Following the six group supervisions, individual semi-structured interviews were conducted with participants from November to December 2016.

\subsubsection{Interview Location}

The participants were interviewed in a location where they could speak calmly and openly, so as to encourage honest and forthright communication.

\subsubsection{Data Collection Method}

A semi-structured interview format was used and each interview lasted approximately 40 minutes. A verbatim record from each interview was created on an IC recorder.

\subsubsection{Question Contents}

The main interview questions were as follows:

1. How was the group supervision (GSV)?

2. What did you think about receiving GSV?

3. What changed for you after receiving GSV, and what was the cause of that change? 


\subsection{Ethical Considerations}

In conducting the research, we obtained the approval of the Ethics Committee of Takasaki Health and Welfare University (Takasaki Health Unit No. 2760).

\subsection{Analysis of Interview Contents}

In this study, we used the Modified Grounded Theory Approach (M-GTA), an empirical and functional research method, for data analysis. M-GTA is a qualitative research methodology developed by Japanese sociologist Yasuto Kinoshita. It is a method for extracting concepts that help explain human thoughts and behaviors. We adopted M-GTA to discover how Yogo teachers' cognition, thinking, and actions changed after receiving GSV.

The analysis theme was "Change in Yogo teachers' cognition, thinking, and actions after GSV." The focus of the analysis was "Yogo teachers who participated in GSV." The process was as follows. First, we extracted common concepts from the participants' interview data. We then examined the relationships between the extracted concepts and generated categories of similar concepts. During that stage, we created analytic worksheets, which comprised a series of formats for generating concepts from data, worksheets, definitions, concept names, and theoretical notes. To preserve the reliability and validity of the research, one researcher consistently performed data collection and analysis, after which the collaborators examined the data, concepts, and categories.

The researchers created a storyline to demonstrate the relationship between categories, with reference to their own educational experience and prior research, as shown in Figure 1. We used symbols to indicate different findings. The generated concepts are marked with $<$, while the categories are marked with []. Data are indicated with $\ulcorner$, and supplementary explanations are added with () as necessary.

The qualitative data were analyzed using M-GTA, resulting in 14 concepts and six categories as shown in Table 2.

\section{Results}

Table 2. Categories and concepts

\begin{tabular}{|c|c|c|}
\hline Category & Concept & Definition of concept \\
\hline \multirow[t]{2}{*}{ Emotional Support } & Learning from supervisor & Learning from the words and attitudes of the supervisor \\
\hline & $\begin{array}{l}\text { Interaction with other Yogo } \\
\text { teachers }\end{array}$ & $\begin{array}{l}\text { Understanding and empathy within exchanges between professional } \\
\text { associates }\end{array}$ \\
\hline \multirow[t]{2}{*}{ Awareness } & Awareness of self & $\begin{array}{l}\begin{array}{l}\text { Realizing own characteristics (personality and attitude toward } \\
\text { children) }\end{array} \\
\end{array}$ \\
\hline & Awareness of child correspondence & $\begin{array}{l}\text { Reviewing the usual child correspondence and noticing the approach } \\
\text { from a different angle }\end{array}$ \\
\hline \multirow[t]{4}{*}{ Systemic Thinking } & Broadening the field of vision & $\begin{array}{l}\text { Why it's important for Yogo teachers to consider each case } \\
\text { systematically }\end{array}$ \\
\hline & $\begin{array}{l}\text { Considering other people around } \\
\text { children }\end{array}$ & $\begin{array}{l}\text { Understood that it is important to think about other people related to } \\
\text { the case }\end{array}$ \\
\hline & Importance of visualizing & $\begin{array}{l}\text { Importance of concretization and visualization of supervisor's } \\
\text { feedback }\end{array}$ \\
\hline & Observation while being involved & Objectively observing the relationship between you and each child \\
\hline \multirow[t]{3}{*}{ Collaboration } & Importance of collaboration & $\begin{array}{l}\text { Understanding why it's important that Yogo teachers collaborate with } \\
\text { people related to children }\end{array}$ \\
\hline & $\begin{array}{l}\text { Deepening understanding of other } \\
\text { teachers }\end{array}$ & $\begin{array}{l}\text { Understanding the ways colleagues and homeroom teachers think and } \\
\text { feel }\end{array}$ \\
\hline & $\begin{array}{l}\text { Deepening understanding of family } \\
\text { members }\end{array}$ & How Yogo teachers understand and support the family \\
\hline \multirow{2}{*}{$\begin{array}{l}\text { Motivation } \\
\text { Improvement }\end{array}$} & Improvement of self-motivation & Motivation for Yogo teachers to work on cases to improve \\
\hline & $\begin{array}{l}\text { Importance of the role of Yogo } \\
\text { teachers }\end{array}$ & How Yogo teachers realize their importance in education settings \\
\hline Training Location & Appreciating Supervision & How Yogo teachers realize the effects and significance of supervision \\
\hline
\end{tabular}

An explanation of each generated category and its related concepts is as follows.

Category 1: Emotional Support

[Emotional Support] was composed of the concepts <Interaction with other Yogo teachers $>$ and $<$ Learning from supervisor>.

$<$ Interaction with other Yogo teachers> offered the following example as part of the data set: "There are so many problems because it is a one-man job. I understood from the stories of other Yogo teachers that I would not experience much support." 
$<$ Learning from supervisor $>$ offered the following example from the data set: "From the supervisor, you got only the basic question of what you want to do objectively, and you got a hint of what you would see of children's minds."

Category 2: Awareness

This category consisted of two concepts: $<$ Awareness of self $>$ and $<$ Awareness of child correspondence $>$.

$<$ Awareness of self $>$ offered the following data example from one participant: "I did not analyze myself so much...I thought about how I am...I could stare at unfavorable parts of my practice, for instance, look at an unconscious behavior pattern that I noticed in my personality traits."

$<$ Awareness of child correspondence $>$ offered the following data example, which the participant framed as a question: "What is in the child's heart? It became possible to see the child's background, that is, seeing that the child or their family is in trouble." Notably, this participant offered an approach from a different angle than other participants.

Category 3: Systemic Thinking

This category consisted of four concepts: $<$ Broadening the field of vision $>,<$ Considering other people around children $>$, $<$ Importance of visualizing $>$, and $<$ Observation while being involved $>$.

In the example of the data of $<$ Broadening the field of vision $>$, one respondent replied, "I thought that my interest in evaluating individuals independently from other people, thinking about the relationship between parents and children, and asking the opinions of school counselors at an early stage, all provoked further awareness."

$<$ Considering other people around children $>$ asked participants to consider which other people in the child's life might impact the child's experience. One respondent said it made them "think about all the characters."

$<$ Importance of visualizing > offered the following data example: "I have seen and heard that the characters and positional relationships are written and described by the Yogo teacher, but I felt it was important to watch it actually done by my supervisor."

$<$ Observation while being involved $>$ offered the following data example: "I was trying to get rid of the negative connotations if I said that the child was hard to deal with. So, I began to think about how the child would respond to a difficult relationship with me."

\section{Category 4: Collaboration}

Collaboration was composed of three concepts: $<$ Importance of collaboration $>$, $<$ Deepening understanding of other teachers $>$, and $<$ Deepening understanding of family members $>$.

$<$ Importance of collaboration $>$ offered the following example from the data set: "I knew that the whole team was involved with the child who was in trouble."

$<$ Deepening understanding of other teachers $>$ offered the following data example: "Because I feel a certain way when I am in charge of teaching, I think in only that way...but when I started to think of the homeroom teacher and child together, I began to care more about what other teachers think."

$<$ Deepening understanding of family members $>$ offered the following data example: "I want to create relationships with mothers and families as early as possible, to learn things such as how they are engaged with their children, or how they themselves change."

\section{Category 5: Motivation Improvement}

Improvement in motivation consisted of two concepts: $<$ Improvement of self-motivation $>$ and $<$ Importance of the role of Yogo teachers>.

$<$ Improvement of self-motivation> offered the following data example: "I thought about why I should do my job...I looked back at my style of work and thought about it."

$<$ Importance of the role of Yogo teachers> offered the following data example: "Since the counselor does not come every day, the health room is important, so we need to connect the counselor with daily information about the students." The participants' remarks on the importance of Yogo teachers to the educational site were notable for their outstanding enthusiasm. 


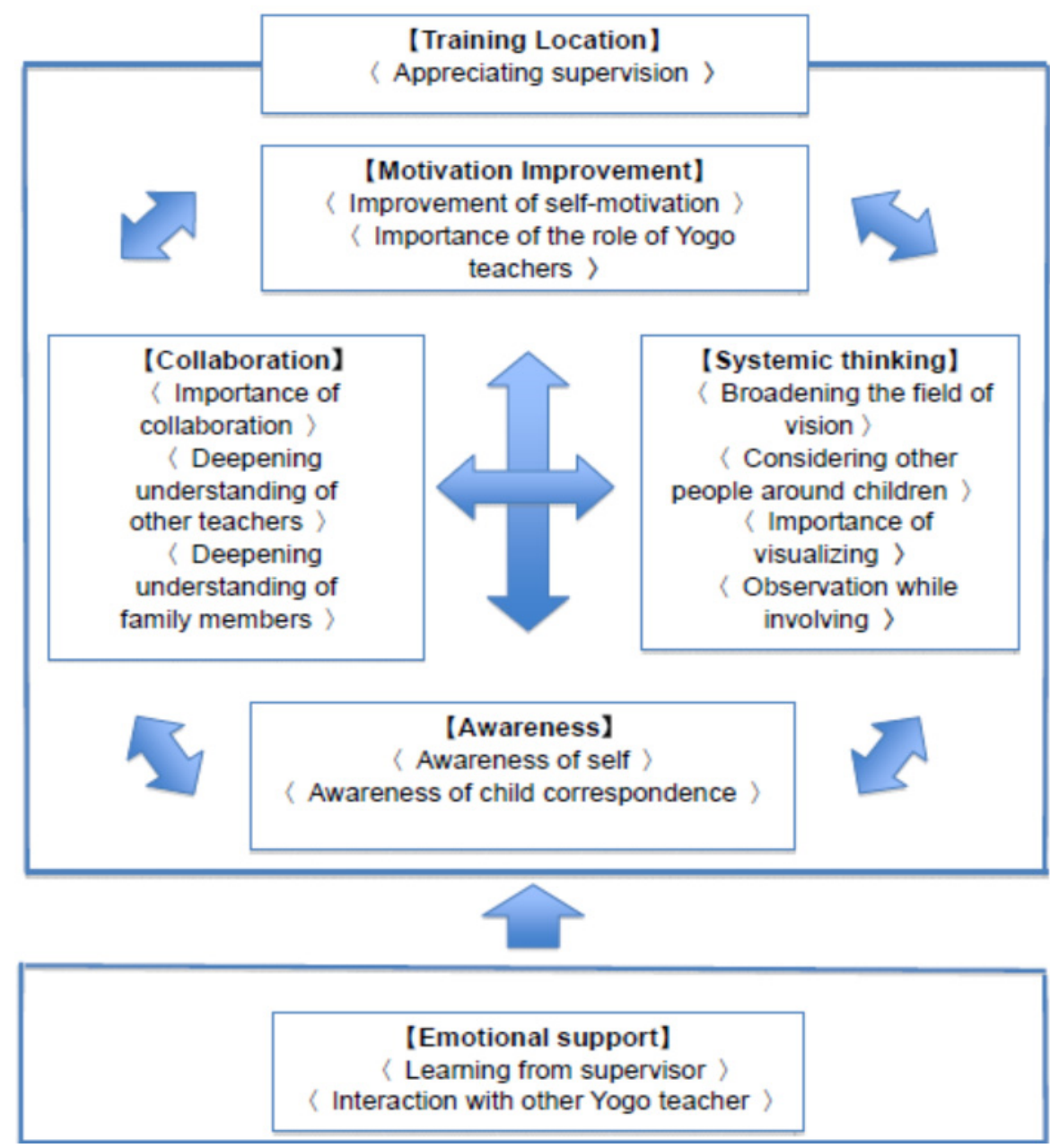

Figure 1. The knowledge and skill change process of Yogo teachers who have received supervision from a family therapist

Category 6: Training Location

This category consisted of one concept: <Appreciating Supervision>. Responses included the following: "Since becoming a Yogo teacher, I have not collaborated with other professionals...but I believe consultation is important, plus I want an environment in which to learn. I think it is good to talk about my weaknesses and how to improve. I want to continuously receive supervision. I realized the significance of supervision as a part of training."

\section{Discussion}

In this study, we conducted a nationwide survey to clarify the difficulties encountered by Yogo teachers and the knowledge and skills necessary for Yogo teachers in Japan. We found that many Yogo teachers require understanding of, as well as the skills to address, children's mental health care. It became clear that cooperation with professionals such as psychiatrists and clinical psychologists is indispensable. We also found that parent-child relationships and family problems are often deeply involved in the creation and maintenance of students' psychological problems, and that close collaboration with supervisors can help Yogo teachers effectively reach their students. The authors examined the effects of supervision on Yogo teachers, and discussed the findings with psychiatrists as well as with members of the Japan Association of Family Therapy Certified supervisors.

Regarding the cooperation of expert teachers and mental health professionals, Karaki, Takamiya, and Isobe (2008) pointed out the importance of the following in dealing with children's problems: the case study meeting, discussion of concrete aid methods with Yogo teachers from other schools, and knowledge from medical experts. They also noted the significance of the case study meeting as a place in which to learn. Matsunaga, Saito, and Uehara (2014) analyzed the value of a one-time "case study meeting," followed by a review meeting with the case provider six months later. They reported that Yogo teachers and their professional associates recognized confidently that such meetings were useful and necessary.

These two previous studies clearly demonstrated that Yogo teachers require case studies in groups. Our study followed the same methodological model by conducting monthly supervision sessions overseen by psychiatrists and family 
therapists. Our aim was to demonstrate the training effectiveness of supervision for Yogo teachers' understanding of child psychology and also for improving their responsiveness to families. We therefore emphasized the following six categories, which were generated from our research.

\subsection{Emotional Support}

This category consisted of $<$ Learning from supervisor $>$ and $<$ Interaction with other Yogo teachers $>$. The multiple placement rate of Yogo teachers remains low at $12.1 \%$, even in the school health room usage investigation booklet (Japanese Society of School Health, 2011). Therefore, many Yogo teachers have no opportunity to observe how Yogo teachers at other schools work, and thus many are solitary workers who get by without consulting with their peers in their own or other institutions. In relation to the problem of Yogo teachers' placement, Ishida and Sonoda (2016) found that, when comparing an isolated Yogo teacher with one who had benefited from interaction with multiple Yogo teachers, one main topic of discussion was "children with mental health problems." In their study, the isolated Yogo teacher was concerned and had consulted with the Yogo teacher of another school. Their exchange influenced the reduction in the first Yogo teacher's anxiety and loneliness. The study participants indicated that their exchange with other Yogo teachers, as well as the presence of a supervisor, led them to feel more emotionally supported. From an objective viewpoint, exchanges with other Yogo teachers, in addition to the effect of a supervisor who employs empathy and warmth toward them, are very influential.

\subsection{Awareness}

This category consisted of two concepts: $<$ Awareness of self $>$ and $<$ Awareness of child correspondence $>$.

One Yogo teacher observed children's behavior characteristics in daily practice tasks. With the help of other Yogo teachers' remarks and a supervisor's advice, the teacher brought a new awareness back to the routine practice of teaching. This helped us to realize that we can respond to children's problem behaviors appropriately in our daily work. Kouno et al. (2013b) reported the necessity of "noticing" in daily practice and "understanding relationships with children." To respond to children, in this study, we also emphasized the importance of the attitude of the Yogo teacher him or herself, which led to an awareness of how deepening their own understanding of their interpersonal relationship patterns leads to self-analysis.

Watanabe (2010) notes that unless mental healthcare experts can face up to their own psychology, they cannot understand the minds of others. Thus, as noted by Pearson (1996), self-analysis is necessary for education. Likewise, the authors of the present study understand that training in psychoanalysis, by providing them with insight into their own inner workings, improves Yogo teachers ability to relate to children. To conduct health counseling activities, it is important to understand one's own history and background. Yogo teachers must understand children and their families, and tend to think that self-understanding will influence how they can empathize with a child's psychology.

Yogo teachers in Japan, however, are often unaware of the importance of self-analysis, as there is currently no training that leads to such. This is one area in which this type of supervision can help Yogo teachers to improve. For example, in my own career, I have received personal supervision, and with that experience, I can reflect on my own employment and my past encounters with Yogo teachers in elementary schools, in order to utilize those reflections in my current work.

\subsection{Systemic Thinking}

This category consisted of four concepts: $<$ Broadening the field of vision $>$, $<$ Considering other people around children $>$, $<$ Importance of visualization $>$, and $<$ Observation while being involved $>$.

Systemic thinking is a way to understand the educational site as a system and to see it from the vantage point of a high position. This thinking occurs by incorporating the viewpoint of the supervisor and other participants. As a result, Yogo teachers deepen their understanding of children as well as the families that influence them. The basic thinking of family therapy is systemic thinking. For instance, family therapy often utilizes a whiteboard to create genograms (family relation charts; McGoldrik, Gerson, \& Shellenberger, 1999; Nakamura, 2002). Using the concept of genogram writing as a figure of systemic thinking is useful for acquiring this mode of thought.

$<$ Observation while being involved $>$ is a concept derived from psychiatrist Harry Stack Sullivan in 1953. Sullivan writes that by "involving" one's empathic understanding in a client's suffering and conflict, a psychiatrist can develop a therapeutic attitude while still maintaining margins to objectively "observe" the client's expression, attitude, and situation. Sullivan's interpersonal relationship theory was a systemic theory important to mid-century psychoanalysis (Sullivan, 1954). Yogo teachers used it to learn the importance of observing while engaging with themselves or those around them.

\subsection{Collaboration}

The important concepts of $<$ Deepening understanding of other teachers $>$ and $<$ Deepening understanding of family members $>$ were extracted in this survey. 
Goto and Huruta (2010) and Ikezoe (2017) point out the importance of collaboration between Yogo teachers, but also note that working together is not always easy. Collaboration is impossible without understanding each participant's position or the purpose of their work. McDaniel, Doherty, and Hepworth (2014) write that collaboration requires showing respect for each other's expertise, which shares and improves upon the quality of care.

In general, collaboration has not been well developed at school sites in Japan. According to the survey conducted by the authors in 2017 (Iwasaki \& Watanabe, 2017), Yogo teachers in Japan showed the most difficulty with collaboration as an educational value (193: 19.1\%). Understanding one's family is the start of cooperating with one's family, but such has been lacking in Yogo teacher training to date. Therefore, learning how to understand family in teacher supervision is helpful.

For example, collaboration succeeded in providing an understanding not only of the children themselves, but also of their family background and being conscious of the need to build collaborative relationships with the families. In one case, collaboration progressed by addressing the mother's feelings and increasing the empathy between her and the Yogo teacher.

In the survey we conducted, within the category of training needs, psychology and psychiatry were the most pressing needs. Improving counseling skills and abilities is required for such training to be effective. Yogo teachers reported that they would like to receive counseling training. To that end, cooperation with mental health care experts (psychiatrists, clinical psychologists, social workers) is foundational.

\subsection{Increasing Motivation}

Motivation was composed of two concepts: <Improvement of self-motivation> and <Importance of the role of Yogo teachers>.

Understanding the significance of awareness and cooperation raises the motivation for work, while at the same time reaffirming the importance of the role of Yogo teachers. For the author personally, it was through emotional support, gaining an understanding of the importance of awareness, and collaboration that I became motivated to work.

It is important for Yogo teachers to know that when people spend their days in a workplace environment of anxiety and conflict, GSV can help them retain and increase their motivation. In relation to stress and depression in Yogo teachers, Nakazawa and Asakura (2016) reported that since Yogo teachers are working alone, it is easy for them to feel lonely and as if they lack understanding of the job. In a survey conducted by Takeda, Okada, and Asakura (2010), 34.2\% of Yogo teachers reported a tendency toward having depression.

Yogo teachers may also be perceived as having a lower status than general teachers, which might affect children's care and stress factors. Yasubayashi (2012) stated that Yogo teachers' "inappropriate evaluation" are influenced by general teachers, so that Yogo teachers report high incidences of thoughts of self-insufficiency and depressed tendencies. In an interview survey with 22 persons in managerial positions (principals and vice-principals), Yasubayashi noted, "The Yogo teacher and clerical workers tend to be seen as lower in the school organization," and "When the Yogo teacher was chosen as the manager, there was a negative reaction from the general teachers."

What managers and general teachers want most in respect to Yogo teachers' overall duties are the traditional role of "judgment and response to emergency measures" (Kubo, 2017). However, in contemporary Japan, Yogo teachers' duties are increasingly based on consulting and higher-level care. The Yogo teachers' "health consultation activity" was born in 1997, when Yogo teachers in Japan began to require counseling training. However, because the roles of Yogo teachers are fully known or appreciated by management staff and general faculty members, many people do not know that Yogo teachers require counseling abilities.

Through GSV, I came to understand the importance of cooperating with Yogo teachers, to acknowledge their consultation needs, to aggressively support their cooperative functions, and so on. Doing so is important to receive support from managers and colleagues (Takeda, 2010). Clearly, the results of this research can increase motivation by emphasizing the support provided by higher self-esteem and work satisfaction.

\subsection{Training Location}

The training location consisted of a single concept, $<$ Knowing Supervision $>$. The theoretical knowledge and skills required for today's Yogo teacher improve their consultation abilities.

The fact that experience in infancy is an important determinant of personality is mere common sense for Japanese people, as illustrated in the saying, "The soul of the three-year-old lasts 'til one hundred." A dynamic psychiatrist will therefore emphasize the patient's childhood experiences, as such experiences may lead to problem behavior and psychiatric symptoms in schools (Gabbard, 2005). For example, children who suffer physical abuse and school non-attendance often suffer from mental illness and social withdrawal in adulthood. Similarly, patterns of mutual relationships within families can maintain or augment the disease conditions in a child. 
In Japan, there is the concept of "going straight to the infirmary in school," which means "a student who stays in the health room at all times or attends a specific class, with most of the students who are at school being enrolled in the health department" (Ministry of Education, 2011).

Family problems often influence the practice of going straight to the infirmary in school; as a result, the authors understand that children view Yogo teachers and the health department as supplementary family members, in a way. It is important to understand the health room as a place where an individual can relax just as they can with their family, feel relief, recognize their growth, and nurture themselves. Supervision is important for Yogo teachers to understand their work from these perspectives; if they can see themselves as an extension of the family in some sense, they will be able to provide better care for their students.

With Yogo teachers at the center of our focus, we can look to new perspectives by caring for children's minds within both families and schools simultaneously. Yogo teachers can also connect students to School counselor and School social warker for professional care. By participating in group supervision with psychiatrists and/or family therapists, it was found that the existence of supervisors promotes relationship-building between Yogo teachers and other occupations.

\subsection{Storyline}

In qualitative research, it is important to hypothesize the storyline based on the extracted categories (Okamura, 2004; Bailey, 1997). In the current study, we used M-GTA and analyzed the storyline based on the concepts and categories extracted.

Yogo teachers who participated in GSV obtained emotional support through learning from supervisors, exchange with other Yogo teachers, "noticing" (Kouno et al., 2013b), awareness of self, awareness of child correspondence, considering other people around the children, the importance of visualization, observation while being involved, learning systemic thinking, understanding the importance of collaboration, deepening understanding of other teachers, and deepening the understanding and support of the family. Further, this led to improved self-motivation, recognizing the important role of Yogo teachers, and increased motivation to work. Overall, participants gained better insights and appropriate training.

\section{Conclusion}

In this study, eight Yogo teachers experienced GSV once a month for two hours at a time, six times in total. After the sixth session, the authors conducted a semi-structured interview with the teachers in relation to their "GSV experience." The obtained interview data were analyzed using M-GTA (Modified Grounded Theory Approach). As a result, 14 concepts and six categories based on these concepts were generated. Yogo teachers' participation in the group supervision indicated that their consciousness change process model is as follows: their awareness was deepened by receiving emotional support, by training with the intent to learn, and by considering the significance of collaboration. Overall, teachers experienced an increase in self-motivation. The process for "Improvement of consultation ability" became clear. Finally, it was found that group supervision by psychiatrists and/or family therapists had a positive impact on the overall motivation and work efficacy of Yogo teachers in Japan.

\section{References}

Bailey, D. M. (1997). Research for the health professional: A practical guide (2nd ed.). Philadelphia, PA: F. A. Davis.

Gabbard, G. O. (2005). Psychodynamic psychiatry in clinical practice (4th ed.). Arlington, VA: American Psychiatric Press.

Goto, T., \& Huruta, S. (2010). A study of the leadership activities of Yogo teachers during collaborations in the school health programs. Japanese Journal of School Health, 53(4), 191-205.

Ikezoe, S. (2017). Interdisciplinary team approach to respect each child's personality and individuality. Japanese Journal of School Health, 58(6), 326-327.

Ishida, Y., \& Sonoda, N. (2016). Relationship between self-education ability in solitary school nurse arrangements and job difficulties. Japanese Journal of Applied Psychology, 42(1), 12-19.

Iwasaki, K. (2015). Undeclared issues discovered during health consultations with children visiting the school health room-Connected to the duties of the Yogo teacher. Japanese Association of Health Consultation Activity, 10(1), 45.

Iwasaki, K., \& Watanabe, T. (2016). Recent research trends in service training of Yogo teachers, Journal of Japanese Association of Health Consultation Activity, 11(1), 16-31.

Iwasaki, K., \& Watanabe, T. (2017). Tasks currently faced by Yogo teachers in Japan. International Journal of Education, 9(1), 126-144. https://doi.org/10.5296/ije.v9i1.10661

Japanese Society of School Health. (2011). Investigation result of year 2011: The school health room usage investigation booklet. http://www.gakkohoken.jp/book/ebook/ebook_H240070/\#1 
Karaki, M., Takamiya, S., \& Isobe, M. (2008). The effects of the workshop held by the case study meeting for adolescents: Physical and mental status in order to promote cooperation among school nurses from different schools. Medical Online, 17(2), 122-130.

Kouno, C., Sunamura, K., Sugiyama, M., Abe, S., Nakagawa, H., Nemoto, M., Otaki, S., \& Otani, H. (2013a). How can school nurses improve their assessment skill? (part 2). Studies in School Health Counseling, 9(2), 129-137.

Kouno, C., Watanabe, Y., Komatsu, K, Takahashi, H., Ichihara, A., Furuya, A., ... Oshima, H. (2013b). School nurses empowered by case studies: In the case of common treatment of students in the school nurse's room. Studies in School Health Counseling, 10(1), 57-65.

Kubo, M. (2017). Expectations for the role of Yogo teachers - A comparison between the awareness of Yogo teachers and expectations of their colleagues. Japanese Journal of School Health, 58(6), 361-372.

Matsunaga, M., Saito, F., \& Uehara, Y. (2014) Exploring the optimal way of discussing case studies: An analysis of the interview with case provider. Studies in School Health Counseling, 10(2), 141-149.

McDaniel, S. H., Doherty, W. J., \& Hepworth, J. (2014). Medical family therapy and integrated care (2nd ed.). Washington, D.C., USA: American Psychological Association. https://doi.org/10.1037/14256-000

McGoldrik, M., Gerson, R., \& Shellenberger, S. (1999). Genograms: Assessment and Intervention (2nd ed.). New York, NY: Norton.

Miki, T. (2013). Health consultation and health consultation activities based on the law, concepts, and practice. Japanese Journal of School Health, 54(6), 481-486.

Ministry of Education, Culture, Sports, Science and Technology. (2010). Children's health consult and healthcare instructions booklet for school employees. Available at http://www.mext.go.jp/a_menu/kenko/hoken/_icsFiles/afieldfile/2013/10/02/1309933_01_1.pdf

Nakamura, S. (2002). New genogram format (Mini review of family therapy). Japanese Journal of Family Therapy, 19, 259-262.

Nakazawa, R., \& Asakura, T. (2016). Relation between work-related stressors and depression in Yogo teachers. Japanese Journal of School Health, 57(6), 304-322.

Okamura, J. (2004). An introduction of qualitative research to nursing. Journal of Okinawa Profectural College of Nursing, 5, 3-15.

Pearson. G. H. J. (1996). Psychoanalysis and the education of the child. New York, NY: Norton.

Sullivan, H. S. (1953). The psychiatric interview. New York, NY: Norton.

Sullivan, H. S. (1954). The interpersonal theory of psychiatry. New York, NY: Norton.

Takeda, F., Asakura, T., \& Okada, K. (2010). Factors related to the job satisfaction of Yogo teachers: An investigation of occupational stressors, social support, and self-esteem. The Japanese Journal of Health \& Human Ecology, 76(6), 253-263. https://doi.org/10.3861/jshhe.76.253

Takeda, F., Okada, K., \& Asakura, T. (2010). The relationship between depression and stressor factors in Yogo Teachers: A study at public primary and secondary schools in urban areas. Japanese Society of Health Education and Promotion, 18(2), 92-102.

Watanabe, T. (2010). The things that my family of origin left for me. Japanese Journal of Family Therapy, 27(2), 162165.

Yasubayashi, N. (2012). Role of Yogo teachers at the intersection of public health and education: Findings from an interview survey of school administration officials. The Japanese Society of Health and Medical Sociology, 23(1), $74-84$.

\section{Copyrights}

Copyright for this article is retained by the author(s), with first publication rights granted to the journal.

This is an open-access article distributed under the terms and conditions of the Creative Commons Attribution license which permits unrestricted use, distribution, and reproduction in any medium, provided the original work is properly cited. 